\title{
Italian Society for Rheumatology recommendations for the management of hand osteoarthritis
}

M. Manara1 , A. Bortoluzzi², M. Favero ${ }^{3}$, I. Prevete ${ }^{4}$, C.A. Sciré1, G. Bagnato5, G. Bianchi ${ }^{6}$, M. Ceruso ${ }^{7}$, G.A. Checchia ${ }^{8}$, G.M. D'Avola ${ }^{9}$, G. Di Giacinto ${ }^{10}$, B. Frediani ${ }^{11}$, A. Lombardi ${ }^{12}$, A. Mannoni ${ }^{13}$, G. Mascheroni ${ }^{14}$, M. Matucci Cerinic ${ }^{15}$, L. Punzi ${ }^{3}$, P. Richelmi ${ }^{16}$, M. Scarpellini ${ }^{17}$, F. Torretta ${ }^{18}$, A. Migliore ${ }^{19}$, R. Ramonda ${ }^{3}$, G. Minisola ${ }^{4}$

${ }^{1}$ Epidemiology Unit, Italian Society for Rheumatology (SIR), Milano, Italy; SIR; ${ }^{2}$ Rheumatology Unit, Department of Clinical and Experimental Medicine, Ferrara University, S. Anna University Hospital, Ferrara, Italy; SIR; ${ }^{3}$ Rheumatology Unit, Department of Medicine DIMED, University of Padova, Italy; SIR; ${ }^{4}$ Rheumatology Unit, S. Camillo Hospital, Roma, Italy; SIR; ${ }^{5}$ Rheumatology Unit, Department of Clinical and Experimental Medicine, Policlinico di Messina University Hospital, Messina, Italy; SIR;

${ }^{6}$ Rheumatology Unit, Azienda Sanitaria Locale 3, Genova, Italy; SIR; ' ${ }^{7}$ epartment of Hand Surgery and Microsurgery, Careggi University Hospital, Firenze, Italy; Italian Society of Hand Surgery (SICM);

${ }^{8}$ Recovery and functional rehabilitation Service, Santa Corona Hospital, Pietra Ligure (SV), Italy; Italian Society of Physical Therapy and Rehabilitation (SIMFER); ${ }^{9}$ Rheumatology and Osteoporosis Service, ASP3 Catania, Italy; SIR; ${ }^{10}$ General Practitioner, ASUR Marche, Urbino, Italy; Italian Interdisciplinary Society of Primary Care (SIICP); ${ }^{11}$ Rheumatology Section, Department of Clinical Medicine and Immunology, University of Siena, Siena, Italy; SIR; ${ }^{12}$ General practitioner, Azienda Sanitaria Locale 10, Firenze, Italy; Scientific Society of General Practitioners, Italian Federation of Family Doctors (Metis-FIMMG); ${ }^{13}$ Department of Medicine and Medical Specialties, Azienda Sanitaria Firenze, Italy; SIR;

${ }^{14}$ General practitioner, Carate Brianza (MB), Italy; Italian Society of General Medicine (SIMG);

${ }^{15}$ Department of Biomedicine, Division of Rheumatology AOUC, Firenze, Italy; Department of Clinical and Experimental Medicine, University of Firenze, Firenze, Italy; SIR; ${ }^{16}$ Department of Internal Medicine, University of Pavia, Pavia, Italy; Italian Medical Association of Hydroclimatology, Talassotherapy and Physical Therapy (AMIITTF);

${ }^{17}$ Rheumatology Unit, Fornaroli Hospital, Magenta, Italy; SIR; ${ }^{18}$ Hand Surgery Unit, Gaetano Pini Institute, Milano, Italy; Italian Society of Orthopaedics and Traumatology (SIOT); ${ }^{19}$ Rheumatology Unit, San Pietro Hospital, Roma, Italy; SIR

\begin{abstract}
Hand osteoarthritis (OA) is a common and potentially disabling disease, with different features from hip and knee OA so that a specific therapeutic approach is required. Evidence based recommendations for the management of hand OA were developed by the European League Against Rheumatism (EULAR) in 2006. The Italian Society for Rheumatology (SIR) aimed to update, adapt to national contest and disseminate the EULAR recommendations for the management of hand OA.

The multidisciplinary group of experts included specialists involved in the management of patients with hand OA. In order to maintain consistency with EULAR recommendations, a similar methodology was utilized by the Italian group. The original propositions were reformulated in terms of a search query and for every recommendation a systematic search was conducted updating EULAR recommendations' review. The propositions were translated in Italian and reformulated basing on collected evidences and expert opinion. The strength of recommendation was measured for each proposition with the EULAR ordinal and visual analogue scales.

The original 11 propositions of EULAR recommendations were translated and adapted to Italian context. Further evidences were collected about non-pharmacological therapies, local treatments, intra-articular injection with SYSADOA and corticosteroids, and surgery.

The SIR has developed updated recommendations for the management of hand OA adapted to the Italian healthcare system. Their implementation in clinical practice is expected to improve the management of patients with hand OA.
\end{abstract}

Key words: Hand osteoarthritis, Treatment, Recommendations.
Corresponding author:

Maria Manara

Società Italiana di Reumatologia Via Turati, 40 - 20121 Milano, Italy E-mail: maria.manara@gmail.com 


\section{INTRODUCTION}

$\mathrm{H}$ and osteoarthritis (OA) is a common condition (1) with a significant impact on the patient with regards to pain, disability and limitation in activities of daily living (2-4). Some clinical characteristics considerably differentiate $\mathrm{OA}$ in the hand from that in other sites, such as the hip and the knee, amongst which are a small correlation between radiological lesions and pain, and a large aesthetic impact (4). Moreover, the specific anatomical, functional and prognostic aspects lead to the postulation that the treatment modalities can themselves have a different impact from that observed in the large joints (5).

In 2006 a European League Against Rheumatism (EULAR) Task Force has issued evidence-based recommendations on hand OA (6). The Italian Society for Rheumatology (SIR), with the aim of facilitating the dissemination of the proposals in the Italian standpoint, has planned to adapt, update and disseminate the 2006 EULAR recommendations for the treatment of hand $\mathrm{OA}$.

\section{MATERIALS AND METHODS}

Italian recommendations for the management of hand OA were developed by a multidisciplinary team of experts including rheumatologists and other specialists involved in the care of patients with hand arthritis, representatives of the Italian Society of Hand Surgery (SICM), the Italian Society of Physical Therapy and Rehabilitation (SIMFER), the Italian Interdisciplinary Society of Primary Care (SIICP), the Scientific Society of General Practitioners - Italian Federation of Family Doctors (Metis-FIMMG), the Italian Society of General Medicine (SIMG), the Italian Medical Association of Hydroclimatology, Talassotherapy and Physical Therapy (AMITTF) and the Italian Society of Orthopaedics and Traumatology (SIOT). The expert panel adhered to the same methodology of the 2006 EULAR recommendations task force in order to guarantee continuity and consistency in content.
The phases of the resolution were: translation of the recommendations, reformulation of propositions as search queries, evidence collection and critical evaluation, and definition of recommendations derived from available evidence and expert advice, adapted to Italian pharmaceutical formulary.

During the first phase, the recommendations were translated from English to Italian and the resulting proposals were evaluated by the internal expert panel. All propositions were rephrased as search queries according to the PICO (Population-Intervention-Comparator-Outcome) strategy. The systematic literature review has been conducted by adhering to the same methodology of the 2006 EULAR guidelines in order to update the previous review in a consistent manner. The same search strategy was utilized for all recommendations by focusing on the keyword hand arthritis, as reported in the EULAR recommendations (Appendix 1 of 6). The review search has therefore been conducted to systematically identify all studies on hand OA while studies including patients with OA at other sites were not systematically sought. The search was undertaken on main electronic bibliographic databases (Medline, Embase and Cochrane Library) in a timeframe from 1/1/2006 (final EULAR revision date) to $15 / 7 / 2012$, and restricting the search to publications in English or Italian and research conducted on human subjects. The search has been enhanced with manual search in the reference lists of the studies included from the electronic search.

Therefore, a specific selection of studies for each recommendation has been performed among studies included in the general literature review. Inclusion criteria have been defined for each query, and subsequently, an ad hoc data extraction table has been developed. The article selection for each query has been conducted by a single reviewer (MM, AB, MF and IP).

With regards to the study design, systematic reviews and meta-analyses, randomized controlled trials (RCT) and controlled studies were included for queries of efficacy and safety. Conversely, cohort stud- 
Table I - Level of evidence.

\begin{tabular}{|l|l|}
\hline Ia & Meta-analysis of randomized controlled trials \\
\hline Ib & Randomized controlled trial \\
\hline Ila & Controlled study without randomization \\
\hline Ill & Quasi-experimental study \\
\hline III & Non-experimental descriptive studies \\
\hline IV & $\begin{array}{l}\text { Expert committee reports or opinion or clinical } \\
\text { experience of respected authorities, or both }\end{array}$ \\
\hline
\end{tabular}

ies, case control and cross-sectional studies were included for the risk factors queries. Case report, narrative reviews and editorials have been excluded for all queries.

Efficacy and security data on drugs reported in RCTs have been combined in meta- analyses where feasible and presented as standard mean deviations [SMD or effect size (ES)], Number Needed to Treat (NNT) or risk ratio (RR), and relative confidence intervals $(\mathrm{CI})$ at $95 \%$. From the clinical perspective, an ES of 0.20 is considered low, 0.5 as moderate and more than 0.80 as high. The NNT is the number of patients who have to be treated in order to obtain one positive outcome (or prevent one negative outcome), and therefore a lower value corresponds to greater efficacy. On the basis of the study design, the impact of risk factors has been expressed as RR or odds ratio (OR). The ES calculations and the

Table II - Propositions and relative strength of recommendation.

\begin{tabular}{|c|c|c|}
\hline Proposition & VAS $(95 \%$ IC) & $A-B \%$ \\
\hline $\begin{array}{l}\text { 1. Optimal management of hand OA requires a combination of non- pharmacological and } \\
\text { pharmacological treatment modalities individualized to the patient's requirements }\end{array}$ & $97(95-99)$ & 100 \\
\hline $\begin{array}{l}\text { 2. Treatment of hand OA should be individualized according to: i) type of OA (nodal, } \\
\text { erosive, post-traumatic); ii) risk factors (age, sex, adverse mechanical factors); iii) } \\
\text { localization and severity of structural change; iv) presence of inflammation; v) level } \\
\text { of pain, disability and restriction of quality of life; vi) comorbidity and co-medication } \\
\text { (including OA at other sites); vii) wishes and expectations of the patient }\end{array}$ & 95 (93-98) & 100 \\
\hline $\begin{array}{l}\text { 3. Education concerning joint protection (how to avoid adverse mechanical factors) } \\
\text { together with an exercise regimen (involving both range of motion and strengthening } \\
\text { exercises) are recommended for all patients with hand OA }\end{array}$ & $80(73-87)$ & 65 \\
\hline $\begin{array}{l}\text { 4. Thermal therapy, local application of heat (for example, paraffin), especially before } \\
\text { exercise, and other physical therapies (for example, laser therapy, magnetotherapy } \\
\text { and ultrasound) can be beneficial treatments }\end{array}$ & $71(63-80)$ & 35 \\
\hline $\begin{array}{l}\text { 5. Splints for thumb base } \mathrm{OA} \text { and orthoses to prevent/correct lateral angulation and } \\
\text { flexion deformity are recommended }\end{array}$ & $73(65-81)$ & 35 \\
\hline $\begin{array}{l}\text { 6. Local pharmacological treatments are preferred over systemic treatments, especially } \\
\text { for mild to moderate pain and when only a few joints are affected. Topical NSAIDs and } \\
\text { other anti-inflammatory preparations are effective and safe treatments for hand OA }\end{array}$ & $71(62-80)$ & 53 \\
\hline $\begin{array}{l}\text { 7. Because of its efficacy and safety paracetamol (up to } 3 \mathrm{~g} / \text { day) is the oral analgesic of } \\
\text { first choice and, if successful, is the preferred long term oral analgesic }\end{array}$ & $79(68-90)$ & 76 \\
\hline $\begin{array}{l}\text { 8. Oral NSAIDs should be used at the lowest effective dose and for the shortest duration } \\
\text { also in patients who respond inadequately to paracetamol. The patient's requirements } \\
\text { and response to treatment should be reevaluated periodically. In patients with } \\
\text { increased gastrointestinal risk, non-selective NSAIDs plus a gastroprotective agent, or } \\
\text { a selective COX-2 inhibitor should be used. In patients with increased cardiovascular } \\
\text { risk, coxibs are contraindicated and non-selective NSAIDs should be used with } \\
\text { caution. }\end{array}$ & $86(82-90)$ & 88 \\
\hline $\begin{array}{l}\text { 9. SYSADOA (for example, glucosamine, chondroitin sulphate, avocado soybean } \\
\text { unsaponifiables, diacerhein, intra-articular hyaluronic acid) may give symptomatic } \\
\text { benefit with low toxicity, but effect sizes are small, suitable patients are not defined } \\
\text { and clinically relevant structure modification, and pharmacoeconomic benefits have } \\
\text { not been established }\end{array}$ & $72(65-79)$ & 29 \\
\hline $\begin{array}{l}\text { 10. Intra-articular injection of long-acting corticosteroid is effective for painful flares of OA, } \\
\text { especially trapeziometacarpal joint OA }\end{array}$ & $82(77-88)$ & 71 \\
\hline $\begin{array}{l}\text { 11. Surgery (for example, trapeziectomy, arthroplasty with ligament reconstruction and } \\
\text { tendon interposition (LRTI) or arthrodesis) can be an effective treatment for severe } \\
\text { thumb base OA and should be considered in patients with marked pain and/or } \\
\text { disability when conservative treatments have failed }\end{array}$ & 85 (78-92) & 88 \\
\hline
\end{tabular}


resulting meta-analyses have been created with Review Manager (Version 5.1. Copenhagen: The Nordic Cochrane Centre, The Cochrane Collaboration, 2011).

As in the EULAR guidelines, the level of evidence for efficacy has been assigned via a pre-established hierarchy according to the design of the studies included under each research query (7) (Tab. I). The search results for the clinical queries consisted of the highest level of evidence possible, and, when a systematic review of RCTs was available, the earlier review was updated. Queries on risk factors and adverse events were based both on RCTs and observational studies. Studies with direct evidence were considered first, i.e. evidence derived from studies on patients with hand OA about which the literature review has been compiled in a systematic manner; indirect evidence, i.e. evidence from studies conducted on subject with OA at other sites, such as the hip and knee, was only included when direct evidence studies were not available.

The strength of recommendation (SOR) was measured for each proposition by utilizing the EULAR A-E ordinal scale $(\mathrm{A}=$ fully recommended; $\mathrm{B}=$ strongly recommended; $\mathrm{C}=$ moderately recommended; $\mathrm{D}=$ weakly recommended; $\mathrm{E}=$ not recommended) and a visual analogue scale (VAS) from 0 to $100 \mathrm{~mm}$ (8), and by taking into consideration both the evidence (efficacy, safety and cost-effectiveness) and the clinical experience (feasibility, acceptability and tolerance). The results of each proposition were reported as mean of the VAS with $95 \% \mathrm{CI}$ and as percentage of SOR $A$ or $B$ (Tab. II).

\section{RESULTS}

\section{Recommendation \#1}

Optimal management of hand OA requires a combination of non-pharmacological and pharmacological treatment modalities individualized to the patient's requirements. Level of evidence: IV.

Strength of recommendation (95\% CI): 97 (95-99).
This proposition was solely translated to Italian since, via unanimous consensus, it was not deemed worth to be modified. Since there are no studies specifically designed to inform this statement, this statement is supported by expert opinion alone (level IV).

\section{Recommendation \#2}

Treatment of hand OA should be individualized according to:

1) type of OA (nodal, erosive, post-traumatic);

2) risk factors (age, sex, adverse mechanical factors);

3) localization and severity of structural change;

4) presence of inflammation;

5) level of pain, disability and restriction of quality of life;

6) comorbidity and co-medication (including OA at other sites); vii) wishes and expectations of the patient.

Level of evidence: III; IV.

Strength of recommendation (95\% CI): 95 (93-98).

This statement includes a number of clinical factors that may be relevant in guiding clinical management. It is known that there are OA subtypes, such as the erosive or inflammatory form, which is related to worse symptoms and outcomes (9). Evidence on the prognostic role of the disease features in hand OA is mainly based on observational studies.

With regards to the type of OA, various studies have evaluated the impact of erosive OA on disease outcomes such as pain, functional disability, radiological progression and aesthetic impact (10-16). These studies suggest that erosive $\mathrm{OA}$ is associated with an increased radiological progression at 6 years [RR $(95 \% \mathrm{CI}): 1.55(1.04 ; 1.88)]$ (12), higher pain severity [ES (95\% CI): $0.42(0.08 ; 0.75)$ ], functional disability [ES (95\% CI): $0.47(0.13 ; 0.81)]$ and a lower patient satisfaction rate on aesthetic outcomes [ES (95\% CI): -0.67 (-1.01; -0.33)] (11).

Similarly, nodal OA seems to be associated with radiological progression at 6 years [RR (95\% CI): $1.94(1.37 ; 2.48)]$ (12). Conversely, patient sex does not seem 
to significantly influence the outcome of hand OA (13).

The localization of OA can also affect the disease outcome: a cross sectional study on 308 patients with hand OA showed that involvement of both carpometacarpal and proximal interphalangeal joints was associated with higher pain severity [ES $(95 \%$ CI): $0.67(0.43 ; 0.91)]$ and functional disability [ES (95\% CI): $0.60(0.37 ; 0.84)]$ when compared to involvement of proximal interphalangeal joints alone (17); conversely, a prospective study with similar recruitment showed that the involvement of the thumb alone was not associated with a worse disease outcome when compared to involvement of other sites [RR for radiological progression at 6 years $(95 \% \mathrm{CI})$ : $1.16(0.91 ; 1.36)](12)$. With regards to structural change, higher radiological scores were associated with increased pain severity and functional disability (18).

The literature review did not identify any study which analyzed the impact of clinically-assessed inflammation on disease outcome. Studies utilizing diagnostic ultrasonography have shown an association between detected effusion or synovitis and an increase in severity of both pain and impact on quality of life $(19,20)$.

Functional disability due to hand OA seems to be associated with a worse quality of life
(21), while OA at other sites does not seem to influence the radiological progression at the hand (22).

In conclusion, some clinical factors, such as the presence of the erosive and nodal subtypes, radiological and functional severity, and involvement of multiple joint groups, show an association with a worse outcome of hand OA in observational studies (level III); for other clinical characteristics, this statement is supported by expert opinion alone (level IV).

\section{Recommendation \#3}

Education concerning joint protection (how to avoid adverse mechanical factors) together with an exercise regimen (involving both range of motion and strengthening exercises) are recommended for all patients with hand OA.

Level of evidence: IV.

Strength of recommendation (95\% CI): 80 (73-87).

While the 2006 EULAR recommendations supported this proposition on expert opinion alone, the literature review update has included a number of studies which analyzed the efficacy of physical exercise in hand $\mathrm{OA}$; however, the substantial heterogeneity of physical therapy interventions and outcome measures did not permit their combined analysis.

Table III - Studies on the efficacy of exercise and joint protection in the treatment of hand osteoarthritis.

\begin{tabular}{|l|l|l|l|l|l|}
\hline Author (year) & No. & Duration & Design & Intervention & Comparator \\
\hline \multicolumn{5}{|l|}{ Exercise and/or joint protection } \\
\hline Dziedzic (2012) & 257 & 1 year & RCT & Education + joint protection + exercise & Education \\
\hline Garfinkel (1994) & 27 & 10 weeks & RCT & Yoga & No treatment \\
\hline Lefler (2004) & 19 & 6 weeks & RCT & Exercise & Placebo \\
\hline Rogers (2009) & 76 & 48 weeks & RCT crossover & Exercise & Placebo \\
\hline Stamm (2002) & 40 & 3 months & RCT & Joint protection + exercise & Placebo \\
\hline Passive mobilization & \multicolumn{5}{l}{} \\
\hline Villafañe (2012) & 60 & 2 months & RCT & Median nerve mobilization & Placebo \\
\hline Villafañe (2012) & 28 & 2 weeks & RCT & $\begin{array}{l}\text { Passive mobilization of trapezio- } \\
\text { metacarpal joint (Maitland) }\end{array}$ & Placebo \\
\hline Villafañe (2011) & 29 & 2 weeks & RCT & $\begin{array}{l}\text { Passive mobilization of carpo- } \\
\text { metacarpal joints (Kalteborn) }\end{array}$ & Placebo \\
\hline Splint and exercise & & & & Joint protection +splint + exercise & Joint protection \\
\hline Boustedt (2009) & 40 & 1 year & CCT & Education +splint + exercise & Education \\
\hline Stukstette (2011) & 151 & 3 months & RCT & Splint + exercise & Splint + exercise \\
\hline Wajon (2005) & 40 & 6 weeks & RCT &
\end{tabular}

$\mathrm{RCT}$, randomized controlled trial; CCT, controlled clinical trial. 
The simultaneous evaluation of numerous physical therapy interventions did not permit to identify the specific effect of the various components. Moreover, according to Cochrane criteria, the majority of the studies carried a high risk of bias (23). The included studies were subdivided in three categories according to the evaluated therapy: physical exercise and/or joint protection (24-28), passive mobilization techniques of the joints or of the nerves of the hand (29-31) and combined physical exercise and joint splinting (32-34) (Tab. III).

Among the studies of the first group, in which the employment of physical exercise and/or joint protection were evaluated, a non-randomized controlled trial of 27 patients analyzed a 10 -week yoga program and showed a significant reduction in pain severity [ES (95\% CI): -1.30 (-2.13;$0.48)]$ and an increase in range of motion [ES $(95 \% \mathrm{CI}): 1.32(0.49 ; 2.14)]$ in the treatment group, although no significant between-group difference in functional improvement and grip strength was found. A 3-month RCT of 40 patients on a combined program of physical exercise and joint protection has shown a significant increase in grip strength in treated patients [ES (95\% CI): $4.46(3.26 ; 5.66)]$ while a significant reduction in pain severity and improvement in function did not result (28). Conversely, recent data suggest greater overall improvement, with respect to a decrease in pain severity and functional disability, in patients on a combined program of physical exercise and joint protection when compared to control patients (24). The other studies did not however show a significant effect of physical exercise on the recorded outcomes $(26,27)$.

In a RCT on 60 patients, Villafane and colleagues have shown a significant decrease in pain severity and an improvement in grip strength secondary to passive mobilization of the radial nerve (29); a significant decrease in pain levels but no improvement in grip strength were shown in 2 RCT utilizing passive mobilization techniques on the trapeziometacarpal (30) and the carpometacarpal (31) joints. These studies however, despite their adequate methodology, have limitations related to sample size, advanced age of the participants and representation of the studied populations.

Lastly, a 1-year non-randomized controlled trial of 40 patients with trapeziometacarpal joint OA compared a combined program of joint protection, physical exercise and joint splintage to joint protection alone (32). A significant reduction in pain severity èES (95\% CI): $0.75(0.06 ; 1.44)+$, improvement in function èES (95\% CI): 0.98 (0.27; $1.68)+$ and decrease in stiffness èES (95\% CI): $0.88(0.18 ; 1.58)+$ were observed in the combined program group when compared to the control group at long term (even at 1 year) follow-up, while grip strength did not show any significant between-group difference. Conversely, another study did not show significant improvement in pain severity and functional disability in patients who were on a combined program of physical exercise and joint splinting rather than education alone (33); in the same way no significant difference was shown between two exercise regimens which included different types of splints (34). However, the results of the studies included in the last group do not permit to identify the distinct effects of physical exercise and joint splinting, and therefore do not provide direct evidence of the efficacy of one or the other intervention.

In conclusion, there is no direct evidence of the efficacy of joint protection and physical exercise in the management of hand OA. Data derived from the included studies do not provide comparable results and consequently do not permit the comparison of the effect of the various interventions. Therefore, this proposition is supported by expert opinion alone (level IV).

\section{Recommendation \#4}

Thermal therapy, local application of heat (for example, paraffin), especially before exercise, and other physical therapies (for example, laser therapy, magnetotherapy and ultrasound) can be beneficial treatments.

Level of evidence: Ib; IV.

Strength of recommendation (95\% CI): 71 (63-80). 
Physical therapies could be of benefit for patients with hand OA. The main objectives to which these modalities should aim are the relief of pain and stiffness and the increase in strength and range of motion.

Seven RCTs from the literature review support this statement; all were conducted on patients with hand $\mathrm{OA}$, were of a duration varying from 3 to 13 weeks, and analyzed the efficacy of various interventions. Of these, 4 RCTs were derived from a 2011 systematic review which evaluated the effect of the various modalities on pain, joint function and overall physical condition of patients with hand OA (35).

Specifically, these studies evaluated the efficacy and safety of the following modalities: acupuncture (36), laser therapy $(37,38)$, infrared heat $(39,40)$, paraffin with topical analgesics (41) and magnetotherapy with balneotherapy (42) (Tab. IV). There were no significant results with regards to the considered outcomes (pain, musculoskeletal function, grip strength, range of motion, stiffness) except that for the last two studies.

In the 4-week study of Myrer (41) on 35 patients the efficacy of the paraffin and topical analgesics was compared to that of the paraffin alone and therefore the difference in effect probably represented the effect of topical anaesthetics alone. The study showed a significant decrease in pain severity [ES (95\% CI): $0.97(0.26 ; 1.67)]$ and increase in hand function [ES (95\% CI): 0.97 $(0.26 ; 1.67)]$ in the group treated with paraffin and topical anaesthetics when compared to the patients treated with paraffin alone.
On the other hand, the 13-week study of Horvath (42) on 63 patients compared the efficacy of balneotherapy with magnetotherapy to that of magnetotherapy alone: in this case therefore, the difference in effect probably represented the role of balneotherapy. The combination of balneotherapy and magnetotherapy resulted in a greater improvement in pain severity [ES $(95 \%$ CI) $0.82(0.18 ; 1.45)]$ and grip strength [ES (95\% CI): $0.70(0.07 ; 1.32)]$ when compared to the application of magnetotherapy alone.

In conclusion, thermal balneotherapy seems to reduce pain severity and improve grip strength in patients with hand OA (level Ib). The local application of heat and that of other physical modalities are supported by expert opinion alone (level IV).

\section{Recommendation \#5}

Splints for thumb base OA and orthoses to prevent/correct lateral angulation and flexion deformity are recommended.

Level of evidence: Ib; IV.

Strength of recommendation (95\% CI): 73 (65-81).

There was no literature on RCTs comparing standard care or placebo to the use of orthoses at the time of publishing of the 2006 EULAR recommendations. The first RCT on trapeziometacarpal joint orthoses was published in 2009 (43) and the literature review update identified another study published in 2010 on a similar intervention (44). Both studies were RCTs in which the use of orthoses in trapeziometacarpal joint OA was compared to standard treatment.

Table IV - Studies on the efficacy of physical therapies in the treatment of hand osteoarthritis.

\begin{tabular}{|l|l|l|l|l|l|}
\hline Author (year) & No. & Duration & Design & Intervention & Comparator \\
\hline Basford (1987) & 81 & 3 weeks & RCT & Laser & Placebo \\
\hline Dickens (1989) & 13 & 2 weeks & RCT & Acupuncture & $\begin{array}{l}\text { Transcutaneous electrical } \\
\text { nerve stimulation (TENS) }\end{array}$ \\
\hline Favaro (1994) & 48 & Not reported & RCT & Infrared radiation & Placebo \\
\hline Brosseau (2005) & 88 & 6 weeks & RCT & Laser & Placebo \\
\hline $\begin{array}{l}\text { Stange-Rezende } \\
\text { (2006) }\end{array}$ & 45 & 3 weeks & $\begin{array}{l}\text { RCT } \\
\text { Crossover }\end{array}$ & Infrared radiation & No treatment \\
\hline Myrer (2011) & 35 & 4 weeks & RCT & Paraffin + topical analgesics & Paraffin \\
\hline Horvath (2012) & 63 & 13 weeks & RCT & $\begin{array}{l}\text { Magnetotherapy + } \\
\text { balneotherapy }\end{array}$ & Magnetotherapy \\
\hline
\end{tabular}

RCT, randomized controlled trial. 
The first study was conducted on 112 patients and was of one-year duration, whereas the second one recruited 60 patients and was of 6-month duration. The main outcome of both studies was a VAS decrease in pain severity, while disability, pinch and grip strength were secondary outcomes.

Overall, data analysis showed a statistically significant decrease in medium-long term pain at 6 months ES (95\% CI): - 1.07 (-1.74; $-0.4)$ by Gomes Carreira, and at 1 year ES (95\% CI): -0.69 (-1.10;-0.28) by Rannou), although no significant between-group differences were observed in levels of disability, pinch and grip strength. In both studies, the effect of splinting on trapeziometacarpal dislocation was not analyzed. However, expert opinion recommends that splinting is used during rest (from activity or during sleep) since the device maintaining the joint in a functional position would prevent and correct dislocation of the thumb in trapeziometacarpal joint OA.

In conclusion, RCTs show that the use of a splint or of orthoses during night time or during rest is beneficial in the reduction of pain severity in trapeziometacarpal joint OA (level Ib). Expert opinion suggests that the indication for the prevention and correction of the dislocation of the thumb should be recommended (level IV).

\section{Recommendation \#6}

Local pharmacological treatments are preferred over systemic treatments, especially for mild to moderate pain and when only a few joints are affected. Topical NSAIDs and other anti-inflammatory preparations are effective and safe treatments for hand OA.

Level of evidence: IIb; IV.

Strength of recommendation (95\% CI): 71 (62-80).

The Italian group of experts has omitted the mention of capsaicin since it is not available in the Italian pharmaceutical formulary.

From a 2004 RCT meta-analysis on topical NSAIDs, a subanalysis on hand OA studies has shown that topical NSAIDs have a higher efficacy in pain relief when compared to placebo [ES $(95 \% \mathrm{CI}): 0.77(0.32 ; 1.22)]$ and also have a similar efficacy to that of oral NSAIDs (ES [95\% CI): $-0.05(-0.27$; $0.17)]$ (45). However, the studies included in the subanalysis are of a short duration and show an efficacy of topical NSAIDs higher than placebo in the first 2 weeks, but similar to placebo at 1 month (46-49). The updated literature review has identified other studies on hand OA. In the 21-day study of Widrig on 198 patients, in which the effects of Arnica and ibuprofen gels were compared, no significant difference in pain relief resulted (50). In the 8-week study of Altman on 385 patients, in which the effect of diclofenac sodium gel was compared to that of a placebo, diclofenac showed greater pain relief efficacy despite that this difference seemed to progressively decrease (51). Finally, the comparative study of Jain between topic corticosteroids and placebo did not provide applicable data since the study design was deemed as providing a high risk of bias (52).

With regards to data on safety, the 2004 meta-analysis conducted by Lin showed that topical NSAIDs did not portray a higher risk of gastrointestinal adverse effects than placebo [RR (95\% CI): $0.81(0.43 ; 1.56)]$ (45). Two post-hoc analyses included in this review show that diclofenac gel $1 \%$ (53) and diclofenac solution 1.55\% DMSO (54) are both safe and well tolerated and that their main possible adverse effect is a local cutaneous reaction; there was indeed no observed significant difference when compared to placebo in respect to systemic adverse effects or specifically to adverse effects in the gastrointestinal tract.

In conclusion, topical NSAIDs are an effective therapeutic choice in patients with mild to moderate pain and when only a few joints are affected (level IIb). Their safety profile makes topical NSAIDs indicated for patients with comorbidities or those with a high risk of cardiovascular and gastrointestinal events (level IV) since, with the exception of local cutaneous reactions, they do not seem to cause more adverse effects than placebo (level Ib).

\section{Recommendation \#7}

Because of its efficacy and safety paracetamol (up to $3 \mathrm{~g} /$ day) is the oral an- 
algesic of first choice and, if successful, is the preferred long term oral analgesic.

Level of evidence: IV.

Strength of recommendation (95\% CI): 79 (68-90).

There are no RCTs comparing paracetamol to placebo which show its efficacy in patients with hand $\mathrm{OA}$ even though paracetamol has been indicated for hand OA for decades. Evidence in support of its use is mainly extrapolated from studies on $\mathrm{OA}$ at other sites, such as the hip and the knee. A 2009 Cochrane meta-analysis on the use of paracetamol in patients with hip or knee OA showed that paracetamol has a significantly higher efficacy in pain relief than a placebo (ES (95\% CI): - $0.13(-0.22$; $-0.04)$ ), even though its efficacy is less than that of NSAIDs (55). A head-to-head comparative trial between paracetamol and dexketoprofen trometamol in the treatment of hand OA showed a superior efficacy for the dexketoprofen-trometamol group with regards to reduction in stiffness but not pain (56); moreover, a N-of-1 trial compared paracetamol and celecoxib in patients with OA at different sites, including the hand, and overall $80 \%$ of patients did not report any different effect between the two preparations (57).

However, clinical judgment, apart from efficacy, has to also consider the adverse effects and cost of drugs. In the abovementioned Cochrane meta-analysis, paracetamol did not show a higher risk of adverse effects than that of the placebo [RR (95\% CI): $1.02(0.89 ; 1.17)]$, and also a lower gastrointestinal risk with respect to non-selective NSAIDs [RR (95\% CI): 1.47 $(1.08 ; 2.00)]$ (55). Moreover, data regarding possible paracetamol nephrotoxicity are not decisive, and, at the allowed dosages, hepatotoxicity does not seem to be of concern; on the other hand a clear increase in cardiovascular risk has not been stated even if several studies on the hypertensive effect of paracetamol have been published. Therefore, paracetamol portrays an acceptable balance between risks and benefits and can be considered as first-line analgesic drug in chronic pain conditions, such as OA.
With regards to the use of other analgesics, our literature review did not permit the identification of trials in which these drugs have been studied as an indication for hand OA. A 2009 meta-analysis on the use of tramadol in hip and knee OA has shown a significantly higher efficacy on pain relief when compared to placebo despite the higher risk of both mild and serious adverse effects (58). Similarly, a 2007 meta-analysis on the use of opioid drugs in the treatment of OA at different sites has shown a significant reduction in pain severity [ES (95\% CI): -0.79 (-0.98; $-0.59)$ ] and functional disability [ES $(95 \%$ CI): $-0.31(-0.39 ;-0.24)]$ in treated patients when compared to patients on a placebo; however, opioids use was associated with an increased risk of adverse events with a NNT of 5 (4 for strong opioids, 9 for weak opioids) (59). The Italian expert group has deemed relevant the mention of Law 38 of the $15^{\text {th }}$ of March 2010 and emended on the $31^{\text {st }}$ of March of the same year, which states the possibility to prescribe opioid drugs in the treatment of pain related to chronic degenerative diseases; since that, the prescription of other analgesics can be a therapeutic option in patients not responding to paracetamol.

In conclusion, the efficacy of paracetamol in the management of hand OA has not been shown directly. The proposition is supported by extrapolative evidence from study conducted on OA at other sites (level Ia) and expert opinion (level IV). Although the analgesic effect of paracetamol is inferior to that of NSAIDs, paracetamol is safer and cheaper and therefore is to be considered as first-line analgesic treatment in patients with hand OA. Overall, the proposition is mainly supported by expert opinion (level IV).

\section{Recommendation \#8}

Oral NSAIDs should be used at the lowest effective dose and for the shortest duration also in patients who respond inadequately to paracetamol. The patient's requirements and response to treatment should be reevaluated periodically. In patients with increased gastrointestinal risk, non-selective 
NSAIDs plus a gastroprotective agent, or a selective COX-2 inhibitor should be used. In patients with increased cardiovascular risk, coxibs are contraindicated and nonselective NSAIDs should be used with caution.

Level of evidence: Ia; IV.

Strength of recommendation (95\% CI): 86 (82-90).

As in the published 2006 recommendations, it was not possible to identify any study which specifically analyzed oral NSAIDs use as an indication for hand OA. In the previous recommendations there were only 3-controlled placebo studies on the use of NSAIDs in hand OA. These trials have analyzed the efficacy of meclofenamate $(100 \mathrm{mg}$ t.i.d. for 4 weeks in 41 patients), ibuprofen ( $800 \mathrm{mg}$ daily for 2 weeks in 60 patients) and lumiracoxib (200 $\mathrm{mg}$ or $400 \mathrm{mg}$ daily for 4 weeks in 594 patients). All 3 trials have shown superior efficacy of NSAIDs when compared to a placebo (60-62). From a re-analysis of the data derived from 2 of the 3 studies an ES $(95 \% \mathrm{CI})$ of $0.40(0.20 ; 0.60)$ in reduction in pain severity with a NNT $(95 \% \mathrm{CI})$ of 3 $(2 ; 6)$ were noted.

The updated literature review has identified a study conducted by Yelland and colleagues (57) on a population of patients with OA including a subgroup of patients with hand OA. This N-of-1 trial compared the efficacy of paracetamol and celecoxib by evaluating the individual responses of the participants. Overall, $80 \%$ of patients did not report any difference between the two drugs for all included outcomes (pain, functional disability, stiffness, and adverse events).

Additional information can be derived from a meta-analysis conducted in 2009 (55) which compared the efficacy of paracetamol at a dose of $1 \mathrm{~g}$ for 3 or 4 times daily to that of NSAIDs (including ibuprofen, diclofenac, artrotec, celecox$\mathrm{ib}$, naproxen, rofecoxib) in patients with hip or knee OA. Overall, the efficacy of NSAIDs was reported to be superior to that of paracetamol in pain relief (ES $(95 \% \mathrm{CI})$ : $-0.25(-0.33 ;-0.17))$; moreover, NSAID use has shown to be superior to paracetamol use with regards to the outcomes of function and overall health condition (according to both patient and doctor). There were no reported differences with regards to safety. Detailed analysis of the gastrointestinal risk profile has however shown a statistical difference with regards to treatment cessation due to adverse effects with a RR $(95 \% \mathrm{CI})$ of $2(1.05 ; 3.81)$ for NSAIDs with respect to paracetamol. The renal and cardiovascular safety profiles were not analyzed in this review in light of the rare occurrence of these adverse effects and of the small sample size and the overall short average duration ( 6 days to 2 years) of the included trials, which have not permitted proper analysis of these events.

In line with the previous recommendations, it is appropriate to point up that, since the risk of severe gastrointestinal toxicity is dose-dependent and incremental with age, the indication of NSAIDs for hand OA is to be restricted. Various measures were recommended for gastrointestinal protection with the aim of optimising NSAID use: NSAIDs with proton pump inhibitors (PPIs); NSAIDs with H2-antagonists; NSAIDs with misoprostol; selective COX2 inhibitors (including both COX-2 selective and COX-2 specific, or coxib). There is well-documented evidence that these strategies reduce the risk of gastrointestinal ulcers (55-63). However, extreme caution is necessary to adhere to these strategies since they also carry a potential risk of toxicity (64-66). It seems that cardiorenal toxicity may be a class related side effect of NSAIDs rather than specific of coxibs use, however there is lack of the necessary evidence. In consideration of all risks and benefits, the option of oral NSAID use should be based on the individual conditions of the patient and the decision to use them is to be taken only after an exhaustive and open discussion with the patient.

In conclusion, NSAIDs are effective in the symptomatic treatment of hand OA (Ia). However, NSAIDs carry the risk of serious adverse gastrointestinal effects. Even though the majority of the gastroprotective measures (concomitant prescription of PPIs and the use of selective COX-2 inhibi- 
tors) are able to reduce the NSAID adverse gastrointestinal effects (Ia), their safety profile is still not completely clear (IV).

\section{Recommendation \#9}

SYSADOA (for example, glucosamine, chondroitin sulphate, avocado soybean unsaponifiables, diacerhein, intra-articular hyaluronic acid) may give symptomatic benefit with low toxicity, but effect sizes are small, suitable patients are not defined and clinically relevant structure modification, and pharmacoeconomic benefits have not been established.

Level of evidence: Ib - IV.

Strength of recommendation (95\% CI): 72 (65-79).

Studies on the efficacy of the treatment of hand OA with symptomatic slow acting drugs for OA (SYSADOA) are few and evidence from the previous recommendations has often been extrapolated from studies conducted on patients with hip or knee OA. With regards to glucosamine, the updated review has included a study performed in 2012 (67) with a 6-week follow-up in which the higher efficacy of glucosamine with respect to the control (paracetamol) has been documented in pain relief and functional improvement.

Regarding chondroitin sulphate, the 2006 EULAR recommendations included two studies whose results were deemed as inconclusive: a non-randomized controlled trial (68) comparing the efficacy of combined chondroitin sulphate and naproxen to that of naproxen alone, and a RCT (69) in which chondroitin sulphate or chondroitin polysulphate were compared to a placebo in the prevention of radiological progression at 3 years. The first study (68) has not shown superior efficacy of the combined treatment on naproxen alone; the second one (69) has shown a significantly higher efficacy of the treatment with chondroitin polysulphate [NNT $(95 \% \mathrm{CI}): 8(4 ; 166)]$ but not of the treatment with chondroitin sulphate [NNT (95\% CI): 15 (-12; 15)] with respect to placebo in the prevention of radiological progression. Our review has

Table V - Studies on the efficacy of the treatment with intra-articular hyaluronic acid for hand osteoarthritis.

\begin{tabular}{|c|c|c|c|c|c|}
\hline Author (year) & No. & Duration & Design & Intervention & Comparator \\
\hline Fuchs (2004) & 56 & 26 weeks & $\mathrm{RCT}$ & $31 \mathrm{~mL}$ injections of $\mathrm{HA}$ (Ostelin mini) & $\begin{array}{l}31 \mathrm{~mL} \text { injections of triamcinolone } \\
\text { acetonide (Volon A10) }\end{array}$ \\
\hline Bahadir (2009) & 40 & 12 months & RCT & $15 \mathrm{mg} / 0.5 \mathrm{~mL}$ injection of $\mathrm{HA}$ & $\begin{array}{l}120 \mathrm{mg} / 0.5 \mathrm{~mL} \text { injection of triamcinolone } \\
\text { acetonide }\end{array}$ \\
\hline Figen (2009) & 33 & 6 months & RCT & $11 \mathrm{~mL}$ injection of Hylan G-F 20 & $11 \mathrm{~mL}$ injection of saline solution \\
\hline Heyworth (2008) & 60 & 24 weeks & RCT & $\begin{array}{l}11 \mathrm{~mL} \text { injection of Hylan G-F } 20 \text { for } \\
2 \text { weeks }\end{array}$ & $\begin{array}{l}11 \mathrm{~mL} \text { injection of saline solution, followed } \\
\text { by } 1 \mathrm{~mL} \text { of celestone the following week } \\
\mathrm{OR} \\
11 \mathrm{~mL} \text { injection of saline solution every } 2 \\
\text { weeks }\end{array}$ \\
\hline Roux (2007) & 42 & 3 months & $\mathrm{RCT}$ & $\begin{array}{l}11 \mathrm{~mL} \text { injection of Sodium } \\
\text { Hyaluronidate (Synovial) every } 2 \\
\text { weeks }\end{array}$ & $\begin{array}{l}21 \mathrm{~mL} \text { injections of Sodium Hyaluronidate } \\
\text { (Synovial) every } 2 \text { weeks } \\
\text { OR } \\
31 \mathrm{~mL} \text { injections of Sodium Hyaluronidate } \\
\text { (Synovial) every } 2 \text { weeks }\end{array}$ \\
\hline Schumacher (2004) & 16 & 5 months & $\begin{array}{l}\text { Prospective } \\
\text { cohort }\end{array}$ & $\begin{array}{l}51 \mathrm{~mL} \text { injections of HA } 10 \mathrm{mg} / \mathrm{mL} \\
\text { (MW 500-730 kDa) every week }\end{array}$ & \\
\hline Coaccioli (2006) & 43 & 50 days & $\begin{array}{l}\text { Prospective } \\
\text { cohort }\end{array}$ & $30.5 \mathrm{~mL}$ injections of $\mathrm{HA}$ every week & \\
\hline Mandl (2006) & 32 & 26 weeks & $\begin{array}{l}\text { Prospective } \\
\text { cohort }\end{array}$ & $\begin{array}{l}31 \mathrm{~mL} \text { injections of Hylan G-F } 20 \\
\text { every week }\end{array}$ & \\
\hline Salini (2008) & 18 & 1 month & $\begin{array}{l}\text { Prospective } \\
\text { cohort }\end{array}$ & $\begin{array}{l}11 \mathrm{~mL} \text { ultrasound-guided injection } \\
\text { of } \mathrm{HA} \text { (MW } 0.8-1^{*} 10^{6} \text { Dalton) }\end{array}$ & \\
\hline Frizziero (2012) & 58 & 6 months & $\begin{array}{l}\text { Retrospective } \\
\text { cohort }\end{array}$ & $\begin{array}{l}30.8 \mathrm{~mL} \text { injections of } 10 \mathrm{mg} / \mathrm{ml} \mathrm{HA} \\
\text { (MW 500-730 kDa) every week }\end{array}$ & \\
\hline
\end{tabular}

$\mathrm{RCT}$, randomized controlled trial; HA, hyaluronic acid. 
identified another trial (70) on 162 patients in which treatment with chondroitin sulphate with respect to a placebo has shown superior efficacy at 6 months with regards to pain relief [ES $(95 \% \mathrm{CI}): 0.35(0.04$; $0.66)]$ and improvement in hand function [ES (95\% CI): $0.43(0.12 ; 0.75)]$.

There are no reported studies on the efficacy of the avocado-soya-unsaponifiables complex and diacerhein in the treatment of hand $\mathrm{OA}$; in addition, for the latter, there are reported adverse gastrointestinal effects (diarrhoea).

The evidence supporting the treatment with intra-articular hyaluronic acid in the 2006 EULAR recommendations was extracted from a non-controlled study (71) on 16 patients treated for 5 week with a weekly intra-articular injection of sodium hyaluronate, and on a RCT (72) in which treatment with hyaluronic acid was compared with intra-articular steroid therapy. The updated review has included further studies: four RCTs (73-76), four prospective studies (77-79) and a retrospective study (80) (Tab. V).

The RCTs comparing trapeziometacarpal joint injections of hyaluronic acid to those of a saline solution have not shown statistical differences in the reduction of pain severity and function improvement between the two groups $(73,74)$ even if a statistically significant reduction in pain severity at weeks 12 and 26 with respect to the basal levels was recorded in the hyaluronic group (74). The studies comparing injections with hyaluronic acid and corticosteroids are discussed in proposition $10(72,74,75)$.

A comparison of various treatment regimens (76) has not shown statistically significant difference with regards to pain severity or articular function in groups of patients which were respectively treated with one, two or three weekly intra-articular injections of hyaluronic acid for 2 weeks.

The prospective and retrospective studies on hyaluronic treatment in patients with trapeziometacarpal OA reported a significant reduction in pain and an improvement in hand function at one month $(77,78)$ and six months $(79,80)$ with respect to basal levels.
In conclusion, although new data in support of the efficacy of chondroitin sulphate for hand OA has been published (Ib), evidences present in literature are still inconclusive. There are no published data in the literature on avocado-soya-unsaponifiables complex, diacerhein and glucosamine as indications for hand OA. Despite the lack of evidence on the higher efficacy of hyaluronic acid injection than placebo in patients with symptomatic trapeziometacarpal OA, prospective studies show a reduction in pain severity and an improvement in function with respect to the pre-treatment period (III). Overall, the use of SYSADOA in the management of hand OA is supported by expert opinion (IV).

\section{Recommendation \#10}

Intra-articular injection of long-acting corticosteroid is effective for painful flares of OA, especially trapeziometacarpal joint OA.

Level of evidence: III

Strength of recommendation (95\% CI): 82 (77-88).

In the 2006 EULAR recommendations, the short term efficacy of intra-articular treatment with corticosteroids in patients with symptomatic trapeziometacarpal OA was supported by a non-controlled study (81), and not confirmed by a small RCT which compared the injection with triamcinolone acetonide to one with saline (82). Despite this, expert advice had considered the longacting corticosteroid injection as an effective treatment for the inflammatory phase of OA, especially in that of the trapeziometacarpal joint.

Three RCTs $(72,74,75)$ and 2 prospective studies $(83,84)$ were identified in the updated review. The three-arm RCT of Heyworth and colleagues (74), compared 3 intra-articular injections of combined betametasone sodium and betametasone acetate phosphate, Hylan G-F 20 and saline; there was no statistically significant difference between the 3 groups with respect to the following analyzed variables at 26 weeks: pain, grip strength, pinch strength and range of motion. The study of Bahadir and colleagues (75) compared 3 weekly 
trapeziometacarpal injections of $20 \mathrm{mg}$ triamcinolone acetonide to $5 \mathrm{mg}$ sodium hyaluronate (Ostenil), showing major efficacy of the steroid at 1 month and 6 months with regards to a decrease in pain severity. Moreover, patients treated with corticosteroids experienced, with respect to basal levels, a statistically significant difference in VAS pain reduction at 12 months after the injection, while the decrease in pain among patients treated with sodium hyaluronate was only significant up to 6 months from the start of the study. A RCT comparing $10 \mathrm{mg}$ hyaluronic acid (Ostenil mini) and triamcinolone acetonide (72) has shown superior efficacy on pain of the intra-articular treatment with the steroid in the first weeks of the trial, while in the long term (26 weeks) no statistically significant differences in efficacy were observed between hyaluronic acid and the steroid. Conversely, observational studies have not shown any significant result on the considered outcomes (83, 84).

It is essential however to advise on the considerable heterogeneity among the included studies with regards to the amount of injected drug, the type of corticosteroid and the intra-articular injection techniques opted for since some studies utilized fluoroscopy- or ultrasound-guided injection (82-84).

In conclusion, despite the lack of direct evidence on the higher efficacy of corticosteroid injection with respect to that with saline solution in patients with symptomatic trapeziometacarpal OA, some studies have shown a decrease in pain severity and an improvement in function after treatment with corticosteroids (III). Hence, the multidisciplinary expert group has deemed it proper to consider long-acting corticosteroid injection as an effective treatment for hand OA, especially of the trapeziometacarpal joint.

\section{Recommendation \#11}

Surgery (for example, trapeziectomy, arthroplasty with ligament reconstruction and tendon interposition (LRTI) or arthrodesis) can be an effective treatment for severe thumb base OA and should be con- sidered in patients with marked pain and/ or disability when conservative treatments have failed.

Level of evidence: III

Strength of recommendation (95\% CI): 85 (78-92).

For ethical and methodological reason, there is no available literature on RCTs comparing thumb base surgery and placebo; on the other hand numerous studies support the option of undergoing surgery in cases refractory to conventional treatment. Various studies have been conducted in which different surgical procedures have been evaluated, for each of which there are recognized limitations and peculiarities.

In 2009, the Cochrane Musculoskeletal Group has published a systematic review (85) comprising 9 studies, 8 of which were RCTs and one was a prospective controlled study, with an overall total of 477 participants (range 15-183). The selected analyzed surgical procedures are the following: trapeziectomy, trapeziectomy with ligament reconstruction, trapeziectomy with ligament reconstruction and tendon interposition (LRTI), interposition arthroplasty, trapeziometacarpal arthrodesis and joint prosthetic implantation (Swanson and Artelon). From the literature review, the authors have concluded that it is not possible to identify the superior efficacy of one procedure on another with regards to pain, impact on function, overall health condition, range of movement and strength. With regards to adverse events, the authors have reported that median approach trapeziectomy was complicated by minor cases of adverse events with respect to trapeziectomy with LRTI [RR (95\% CI): 2.20 (1.17; 4.12)].

A second systematic review (86) published in 2011 featured no quantitative data due to the heterogeneity of the included population samples and the differences between the various procedures and between the analyzed outcomes. However, even this review showed that there is no evidence on the superior efficacy of trapeziectomy with LRTI on trapeziectomy alone. With regards to the other procedures, the inclusion of a study on prosthetic joint implantation (87) 
has shown that this procedure can be an option when considering the reported short term benefits, which are immediate joint stability and improvement in strength and range of movement; however, even the authors themselves suggest that the non-optimal methodology of the study necessitates the conduction of clinical trials to compare such procedure with others. Metacarpal osteotomy (88) is to be preferred in the initial phases of OA (I and II according to Eaton). Finally, the studies on carpometacarpal arthrodesis are of low quality and consequently do not permit comparative evidence of the superiority of this procedure on others.

In conclusion, surgery is an effective treatment in patients with trapeziometacarpal OA which is refractory to conventional treatment (level III). The currently available evidence is inconclusive on the higher efficacy and/or safety of the various procedures.

\section{DISCUSSION}

This document presents the SIR recommendations for the management of patients with hand OA based on the 2006 EULAR recommendations (6).

The 2006 EULAR recommendations on hand OA gathered for the recognized need to issue specific indications, which are distinct from those on hip and knee OA, in light of the multiple differences in anatomy, pathological history and the potentially different impact of treatment from that observed in other sites (5).

Similarly, following the organization of an Italian Consensus on the EULAR recommendations on the treatment of knee (89) and hip (90) OA, the SIR has deemed it a priority to update and adapt to the Italian pharmaceutical formulary the EULAR recommendations on the management of hand OA.

The Italian group has resolved to adhere to the EULAR methodology for data collection and evaluation of the strength of the recommendations in order to maintain the existing elements of strength. The sys- tematic literature review has been updated by adhering to the same bibliographic research strategy opted for in the 2006 EULAR recommendations. The levels of evidence in support of the recommendations have been measured by adhering to the same hierarchical scale (7). Moreover, the strength of recommendation has been evaluated through the methodology recommended by the EULAR which assigns a level of evidence on the basis of a visual analogue scale and an ordinal scale. Such approach creates a summary of data on efficacy and safety which is combined with the clinical experience and therefore merges evidence and feasibility instead of merely providing grades of recommendations solely based on the design of the available studies; evaluation has been in fact based upon the opinion of experts who have taken into consideration the efficacy, safety, availability, substainability, logistical challenges and the acceptability of the therapeutic intervention in relation to the perspective of the patient.

Another strong point of the Italian recommendations was wide representation on the expert panel from the whole professional spectrum involved in the care of patients with hand OA, and from both the hospital and the community settings. However, as in the 2006 EULAR recommendations, the representation of the recommendations beneficiaries, that is, the patients affected from hand $\mathrm{OA}$, was not included.

The Italian recommendations have some limitations, mainly with regards to data collection from literature. The compilation of the review from only one reviewer can lead to a heightened risk of loss or erroneous classification of the included studies. Additionally, the employment of validated scales for quality assessment was not ultimately utilized for a formal selection based on the level of quality acquired from this evaluation.

The systematic literature review has shown the scarcity of clinical studies in support of the recommendations which consequently leads to the high proportion of propositions supported by expert opinion alone. Likewise, the literature has shown lack of high 
level evidence in support of various treatment options which consequently lead to a consensus frequently reached with fewer votes in favor: in 6 out of 11 recommendations the proportion of fully or strongly recommended evaluations was $<75 \%$. Moreover, the heterogeneous experience of the experts lead to different results on voting for the strength of recommendations and consequently the precision of confidence intervals was lowered.

During the recommendations development the need for better delineation of the various subsets of hand $\mathrm{OA}$, which differ in both outcome and treatment regimens, became more evident. The systematic review update lead to the introduction and critical analysis of various new studies which however, in most cases, did not advance the level of evidence. For example, the analysis of 11 studies specifically evaluating the efficacy of physical exercise in hand OA did not permit the clear definition of treatment efficacy due to prominent heterogeneity among both treatment modalities and outcome measures; consequently, this prevented the increment in level of evidence for the corresponding recommendation. Comparable observations can be made on the new RCTs identified under recommendation 4 relating to the physical therapies. On the other hand, two new RCTs have lead to the classification of the use of splints and orthoses during sleep and rest under the Ib evidence level as an effective treatment for the alleviation of pain due to trapeziometacarpal OA.

With regards to SYSADOA utilization, our review has lead to the addition of another trial on treatment with chondroitin sulphate which showed efficacy in alleviating pain and increasing function at 6 weeks when compared to a placebo, while 9 studies have been added for the evaluation of intra-articular treatment with hyaluronic acid: 4 RCTs (73-76), 4 prospective studies (77-79) and a retrospective study (80), with respect to only 1 RCT on 16 patients featuring in the 2006 recommendations. RCTs comparing trapeziometacarpal injection with hyaluronic acid and saline solution, despite showing a statistically signifi- cant reduction in pain at 12 and 26 weeks with respect to initial levels, have not shown significant differences between the two groups. Nonetheless it is relevant to highlight that the RCTs included in the review utilized mainly subjective outcomes, and we do not know the effect on structural outcomes, which can be less influenced by the placebo effect (91). On the other hand both prospective and retrospective cohort studies on trapeziometacarpal hyaluronic acid injection report significant pain alleviation and improvement in hand function at 1 month $(77,78)$ and 6 months $(79,80)$ with respect to baseline levels. Moreover, 3 RCTs $(72,74,75)$ and 2 prospective studies $(83,84)$ on the intra-articular administration of steroid-based products have been added, although a notable heterogeneity among these studies with regards to the amount injected, the type of corticosteroid, comparative treatment, evaluated outcomes, observation timeframes and intra-articular injection technique (fluoroscopic or ultrasound guidance) have made unequivocal extrapolation difficult. Lastly, even though the literature review identified another 9 RCT on the various practiced surgical interventions, the identification of superior techniques with regards to pain alleviation and/or functional impact was not possible due to heterogeneity among the studies. Therefore, an increment in level of evidence from the 2006 recommendations was not possible.

In a number of recommendations, in the absence of specific RCTs on hand OA, the recommendations were based upon scientific evidence regarding knee and hip OA. However it is well known that important differences exist between hand OA and that at the knee or the hip with regards to the impact of the disease due to anatomical factors, and also due to different grades of potential disability and functional alteration, natural history, prevalence and risk of disease progression, indicated modalities (e.g. topical preparations, injections) and different response to the same treatments (e.g. NSAIDS or SYSADOA). It is for these reasons that it is debatable whether extrapolations of data from hip and knee 
studies offer a valid and universally acceptable basis for recommendations on the management of hand OA.

On the basis of these observations, the Italian expert group promotes and encourages the development of specific RCTs on the management of hand OA. It is moreover hoped that such studies are conducted in accordance to the 2006 recommendations for the conduction of clinical research on hand OA with the intent of improving the quality of future studies (92).

\section{CONCLUSIONS}

The SIR has developed 11 propositions based on the EULAR recommendations for the management of hand OA, rephrased in line with the availability of new evidence, clinical multidisciplinary experience and the Italian pharmaceutical formulary. The dissemination of the recommendations through the various Italian healthcare sectors and the implementation of the recommendations in clinical practice are to improve the care of patients with hand OA.

\section{REFERENCES}

1. Mannoni A, Briganti MP, Di Bari M, Ferrucci L, Serni U, Masotti G, et al. Prevalence of symptomatic hand osteoarthritis in community-dwelling older persons: the ICARe Dicomano study. Osteoarthritis Cartilage. 2000; 8: S11-3.

2. Dahaghin S, Bierma-Zeinstra SMA, Ginai AZ, Pols HAP, Hazes JMW, Koes BW. Prevalence and pattern of radiographic hand osteoarthritis and association with pain and disability (the Rotterdam study). Ann Rheum Dis. 2005; 64: 682-7.

3. Dahaghin S, Bierma-Zeinstra SMA, Reijman M, Pols HAP, Hazes JMW, Koes BW. Prevalence and determinants of one month hand pain and hand related disability in the elderly (Rotterdam study). Ann Rheum Dis. 2005; 64: 99-104.

4. Zhang YQ, Niu IB, Kelly-Hayes M, Chaisson CE, Aliabadi P, Felson DT. Prevalence of symptomatic hand osteoarthritis and its impact on functional status among the elderly - the Framingham Study. Am J Epidemiol. 2002; 156: 1021-7.

5. Svensson O, Malmenas M, Fajutrao L, Roos EM, Lohmander LS. Greater reduction of knee than hip pain in osteoarthritis treated with naproxen, as evaluated by WOMAC and SF-36. Ann Rheum Dis. 2006; 65: 781-4.

6. Zhang W, Doherty M, Leeb BF, Alekseeva L, Arden NK, Bijlsma JW, et al. EULAR evidence based recommendations for the management of hand osteoarthritis: Report of a Task Force of the EULAR Standing Committee for International Clinical Studies Including Therapeutics (ESCISIT). Ann Rheum Dis. 2007; 66: 377-88.

7. Shekelle PG, Woolf SH, Eccles M, Grimshaw J. Clinical guidelines: developing guidelines (review). BMJ. 1999; 318: 593-6.

8. Zhang W, Doherty M, Arden N, Bannwarth B, Bijlsma J, Gunther KP, et al. EULAR evidence based recommendations for the management of hip osteoarthritis: report of a task force of the EULAR Standing Committee for International Clinical Studies Including Therapeutics (ESCISIT). Ann Rheum Dis. 2005; 64: 669-81.

9. Punzi L, Frigato M, Frallonardo P, Ramonda R. Inflammatory osteoarthritis of the hand. Best Pract Res Clin Rheumatol. 2010; 24: 301-12.

10. Addimanda O, Mancarella L, Dolzani P, Punzi L, Fioravanti A, Pignotti E, et al. Clinical and radiographic distribution of structural damage in erosive and nonerosive hand osteoarthritis. Arthritis Care Res. 2012; 64: 1046-53.

11. Bijsterbosch J, Watt I, Meulenbelt I, Rosendaal FR, Huizinga TW, Kloppenburg M. Clinical burden of erosive hand osteoarthritis and its relationship to nodes. Ann Rheum Dis. 2010; 69: 1784-8.

12. Bijsterbosch J, Watt I, Meulenbelt I, Rosendaal FR, Huizinga TW, Kloppenburg M. Clinical and radiographic disease course of hand osteoarthritis and determinants of outcome after 6 years. Ann Rheum Dis. 2011; 70: 68-73.

13. Hodkinson B, Maheu E, Michon M, Carrat F, Berenbaum F. Assessment and determinants of aesthetic discomfort in hand osteoarthritis. Ann Rheum Dis. 2012; 71: 45-9.

14. Maheu E, Michon M, Carrat F, Berenbaum F. Erosive versus non erosive hand osteoarthritis: prospective cross-sectional comparison of clinical data. Ann Rheum Dis. 2008; 67: 94.

15. Wittoek R, Cruyssen BV, Verbruggen G. Predictors of functional impairment and pain in erosive osteoarthritis of the interphalangeal joints: comparison with controlled inflammatory arthritis. Arthritis Rheum. 2012; 64: 1430-6.

16. Stamm TA, Machold K, Sahinbegovic E, Haider S, Ernst M, Binder A, et al. Daily functioning and health status in patients with hand osteoarthritis: fewer differences between women and men than expected. Wien Klin Wochenschr. 2011; 123: 603-6.

17. Bijsterbosch J, Visser W, Kroon HM, Stamm T, Meulenbelt I, Huizinga TW, et al. Thumb base involvement in symptomatic hand osteoarthritis is associated with more pain and fun- 
ctional disability. Ann Rheum Dis. 2010; 69: 585-7.

18. El-Sherif HE, Kamal R, Moawyah O. Hand osteoarthritis and bone mineral density in postmenopausal women; clinical relevance to hand function, pain and disability. Osteoarthritis Cartilage. 2008; 16: 12-7.

19. Kortekaas MC, Kwok WY, Reijnierse M, Watt I, Huizinga TW, Kloppenburg M. Pain in hand osteoarthritis is associated with inflammation: the value of ultrasound. Ann Rheum Dis. 2010; 69: 1367-9.

20. Keen HI, Wakefield RJ, Grainger AJ, Hensor EM, Emery P, Conaghan PG. An ultrasonographic study of osteoarthritis of the hand: synovitis and its relationship to structural pathology and symptoms. Arthritis Rheum. 2008; 59: 1756-63.

21. Kwok WY, Vliet Vlieland TP, Rosendaal FR, Huizinga TW, Kloppenburg M. Limitations in daily activities are the major determinant of reduced health-related quality of life in patients with hand osteoarthritis. Ann Rheum Dis. 2011; 70: 334-6.

22. Hassett G, Hart DJ, Doyle DV, March L, Spector TD. The relation between progressive osteoarthritis of the knee and long-term progression of osteoarthritis of the hand, hip, and lumbar spine. Ann Rheum Dis. 2006; 65: 623-8.

23. Higgins JPT, Green S. Cochrane Handbook for Systematic Reviews of Interventions Version 5.1.0 (updated March 2011). The Cochrane Collaboration, 2011. Available from: http:// www.cochrane-handbook.org

24. Dziedzic K, Nicholls E, Hill S, Hammond A, Jowett S, Oppong R, et al. The clinical effectiveness of joint protection education and exercises in hand osteoarthritis (OA). Osteoarthritis Cartilage. 2012; 20: S168.

25. Garfinkel MS, Schumacher HR Jr, Husain A, Levy M, Reshetar RA. Evaluation of a yoga based regimen for treatment of osteoarthritis of the hands. J Rheumatol. 1994; 21: 2341-3.

26. Lefler C, Armstrong J. Exercise in the treatment of osteoarthritis in the hands of the elderly. Clin Kinesiol. 2004; 58: 13-6.

27. Rogers MW, Wilder FV. Exercise and hand osteoarthritis symptomatology: a controlled crossover trial. J Hand Ther. 2009; 22: 10-7.

28. Stamm TA, Machold KP, Smolen JS, Fischer S, Redlich K, Graninger W, et al. Joint protection and home hand exercises improve hand function in patients with hand osteoarthritis: a randomized controlled trial. Arthritis Rheum. 2002; 47: 44-9.

29. Villafañe JH, Silva GB, Bishop MD, Fernandez-Carnero J. Radial nerve mobilization decreases pain sensitivity and improves motor performance in patients with thumb carpometacarpal osteoarthritis: a randomized controlled trial. Arch Phys Med Rehabil. 2012; 93: 396-403.
30. Villafañe JH, Silva GB, Fernandez-Carnero J. Effect of thumb joint mobilization on pressure pain threshold in elderly patients with thumb carpometacarpal osteoarthritis. J Manipulative Physiol Ther. 2012; 35: 110-20.

31. Villafañe JH, Silva GB, Diaz-Parreño SA, Fernandez-Carnero J. Hypoalgesic and motor effects of kaltenborn mobilization on elderly patients with secondary thumb carpometacarpal osteoarthritis: a randomized controlled trial. J Manipulative Physiol Ther. 2011; 34: 547-56.

32. Boustedt C, Nordenskiöld U, Lundgren Nilsson A. Effects of a hand-joint protection program with an addition of splinting and exercise: one year follow-up. Clin Rheumatol. 2009; 28: 793-9.

33. Stukstette MJ, Dekker J, Den Broeder AA, Van Der Laan WN, Bijlsma JWJ, Van Den Ende CHM. A multidisciplinary and multidimensional program for hand osteoarthritis is not effective: Results of a randomized controlled study. Arthritis Rheum. 2011; 63: 1570.

34. Wajon A, Ada L. No difference between two splint and exercise regimens for people with osteoarthritis of the thumb: a randomized controlled trial. Aust J Physiother. 2005; 51: 245-9.

35. Ye L, Kalichman L, Spittle A, Dobson F, Bennell $\mathrm{K}$. Effects of rehabilitative interventions on pain, function and physical impairments in people with hand osteoarthritis: a systematic review. Arthritis Res Ther. 2011; 13: R28.

36. Dickens W, Lewith GT. A single-blind, controlled and randomized clinical trial to evaluate the effect of acupuncture in the treatment of trapeziometacarpal osteoarthritis. Complement Medical Res. 1989; 3: 5-8.

37. Brosseau L, Wells G, Marchand S, Gaboury I, Stokes B, Morin M, et al. Randomized controlled trial on low level laser therapy (LLLT) in the treatment of osteoarthritis (OA) of the hand. Lasers Surg Med. 2005; 36: 210-9.

38. Basford JR, Sheffield CG, Mair SD, Ilstrup DM. Low-energy helium neon laser treatment of thumb osteoarthritis. Arch Phys Med Rehabil. 1987; 68: 794-7.

39. Favaro L, Frisoni M, Baffoni L, Ferri ES. Successful treatment of hand erosive osteoarthritis by infrared radiation. Eur Med Phys. 1994, 30: 45-8.

40. Stange-Rezende L, Stamm TA, Schiffert T, Sahinbegovic E, Gaiger A, Smolen J, et al. Clinical study on the effect of infrared radiation of a tiled stove on patients with hand osteoarthritis. Scand J Rheumatol. 2006; 35: 476-80.

41. Myrer JW, Johnson W, Mtchell UH, Measom GJ, Fellingham G. Topical analgesic added to paraffin enhances paraffin bath treatment of individuals with hand osteoarthritis. Disabil Rehabil. 2011; 33: 467-74

42. Horvath K, Kulish A, Nemeth A, Bender T. 
Evaluation of the effect of balneotherapy in patients with osteoarthritis of the hands: a randomized controlled single-blind follow-up study. Clin Rehabil. 2012; 26: 431-41.

43. Rannou F, Dimet J, Boutron I, Baron G, Fayad F, Macé Y, et al. Splint for base-of-thumb osteoarthritis: a randomized trial. Ann Intern Med. 2009; 150: 661-9.

44. Gomes Carreira AC, Jones A, Natour J. Assessment of the effectiveness of a functional splint for osteoarthritis of the trapeziometacarpal joint of the dominant hand: a randomized controlled study. J Rehabil Med. 2010; 42: 469-74.

45. Lin L, Zhang W, Jones A, Doherty M. Efficacy of topical non-steroidal anti-inflammatory drugs in the treatment of osteoarthritis: metaanalysis of randomized controlled trial. BMJ. 2004; 329: 324.

46. Rothacker DQ, Lee I, Littlejohn III TW. Effectiveness of a single topical application of $10 \%$ trolamine salicylate cream in the symptomatic treatment of osteoarthritis. J Clin Rheumatol. 1998; 4: 6-12.

47. Zacher J, Burger KJ, Farber L, Grave M, Abberger H, Bertsch K. Topical diclofenac versus oral ibuprofen: a double blind, randomized clinical trial to demonstrate efficacy and tolerability in patients with activated osteoarthritis of the finger joints (Heberden and/or Bouchard arthritis). Aktuel Rheumatol. 2001; 26: 7-14.

48. Roth SH. A controlled clinical investigation of $3 \%$ diclofenac $2.5 \%$ sodium hyaluronate topical gel in the treatment of uncontrolled pain in chronic oral NSAID users with osteoarthritis. Int J Tiss React. 1995; 17: 129-32.

49. Rothacher D, Difigilo C, Lee I. A clinical trial of topical $10 \%$ trolamine salicylate in osteoarthritis. Curr Ther Res. 1994; 55: 584-97.

50. Widrig R, Suter A, Saller R, Melzer J. Choosing between NSAID and arnica for topical treatment of hand osteoarthritis in a randomized, double-blind study. Rheumatol Int. 2007; 27: 585-91.

51. Altman RD, Dreiser RL, Fisher CL, Chase WF, Dreher DS, Zacher J. Diclofenac sodium gel in patients with primary hand osteoarthritis: a randomized, double-blind, placebo-controlled trial. J Rheumatol. 2009; 36: 1991-9.

52. Jain R, Jain E, Dass AG, Wickstrom O, Walter N, Atkinson PJ. Evaluation of transdermal steroids for trapeziometacarpal arthritis. J Hand Surg Am. 2010; 35: 921-7.

53. Baraf HS, Gold MS, Petruschke RA, Wieman MS. Tolerability of topical diclofenac sodium $1 \%$ gel for osteoarthritis in seniors and patients with comorbidities. Am J Geriatr Pharmacother. 2012; 10: 47-60.

54. Roth SH, Fuller P. Diclofenac sodium topical solution $1.5 \% \mathrm{w} / \mathrm{w}$ with dimethyl sulfoxide compared with placebo for the treatment of osteoarthritis: pooled safety results. Postgrad Med. 2011; 123: 180-8.
55. Towheed TE, Maxwell L, Judd MG, Catton M, Hochberg MC, Wells G. Acetaminophen for osteoarthritis. Cochrane Database Syst Rev. 2006; CD004257.

56. Rovetta G, Monteforte P. Dexketoprofen-trometamol in patients with osteoarthritis of the hands. Minerva Ortop Traumatol. 2001; 52: 27-30.

57. Yelland MJ, Nikles CJ, McNairn N, Del Mar CB, Schluter PJ, Brown RM. Celecoxib compared with sustained-release paracetamol for osteoarthritis: a series of n-of-1 trials. Rheumatology (Oxford). 2007; 46: 135-40.

58. Cepeda MS, Camargo F, Zea C, Valencia L. Tramadol for osteoarthritis. Cochrane Database Syst Rev. 2006; CD005522.

59. Avouac J, Gossec L, Dougados M. Efficacy and safety of opioids for osteoarthritis: a meta-analysis of randomized controlled trials. Osteoarthritis Cartilage. 2007; 15: 957-65.

60. Dreiser RL, Gersberg M, Thomas F, Courcier S, Dreiser RL, Gersberg M, et al. Ibuprofen $800 \mathrm{mg}$ in the treatment of arthrosis of the fingers or rhizarthrosis. Rev Rhum Ed Fr. 1993; 60: 836-41.

61. Grifka JK, Zacher J, Brown JP, Seriolo B, Lee A, Moore A, et al. Efficacy and tolerability of lumiracoxib versus placebo in patients with osteoarthritis of the hand. Clin Exp Rheumatol. 2004; 22: 589-96.

62. Seiler V. Meclofenamate sodium in the treatment of degenerative joint disease of the hand (Heberden nodes). Arzneimittel-Forsch. 1983; 33: 656-9.

63. Rostom A, Dube C, Jolicoeur E, Boucher M, Joyce J. Gastroduodenal ulcers associated with the use of non-steroidal anti-inflammatory drugs: a systematic review of preventive pharmacological interventions. (Technology overview). Ottawa: Canadian Coordinating Office for Health Technology Assessment; 2004.

64. Juni P, Nartey L, Reichenbach S, Sterchi R, Dieppe PA, Egger M. Risk of cardiovascular events and rofecoxib: cumulative metaanalysis. Lancet. 2004; 364: 2021-9.

65. Aldington S, Shirtcliffe P, Weatherall M, Beasley R. Increased risk of cardiovascular events with parecoxib/valdecoxib: a systematic review and metaanalysis. N Z Med J. 2005; 118 : U1755.

66. Solomon SD, McMurray JJV, Pfeffer MA, Wittes J, Fowler R, Finn P, et al. Cardiovascular risk associated with celecoxib in a clinical trial for colorectal adenoma prevention. $\mathrm{N}$ Engl J Med. 2005; 352: 1071-80.

67. Patru S, Marcu IR, Bighea AC, Popescu R. Efficacy of glucosamine sulfate (GS) in hand osteoarthritis. Osteoporosis Int. 2012; 23: S169.

68. Rovetta G, Monteforte P, Molfetta G, Balestra V. Chondroitin sulfate in erosive osteoarthritis 
of the hands. Int J Tissue React. 2002; 24: 2932.

69. Verbruggen G, Goemaere S, Veys EM. Systems to assess the progression of finger joint osteoarthritis and the effects of disease modifying osteoarthritis drugs. Clin Rheumatol. 2002; 21: 231-43.

70. Gabay C, Medinger-Sadowski C, Gascon D, Kolo F, Finckh A. Symptomatic effects of chondroitin 4 and chondroitin 6 sulfate on hand osteoarthritis: a randomized, doubleblind, placebo-controlled clinical trial at a single center. Arthritis Rheum. 2011; 63: 338391.

71. Schumacher HR, Meador R, Sieck M, Mohammed Y. Pilot investigation of hyaluronate injections for first metacarpal-carpal (MC-C) osteoarthritis. J Clin Rheumatol. 2004; 10: 5962.

72. Fuchs S, Monikes R, Wohlmeiner A, Hevse T. Intra-articular hyaluronic acid compared with corticoid injections for the treatment of rhizarthrosis. Osteoarthritis Cartilage. 2006; 14: 82-8.

73. Figen Ayhan F, Ustun N. The evaluation of efficacy and tolerability of Hylan G-F 20 in bilateral thumb base osteoarthritis: 6 months follow-up. Clin Rheumatol. 2009; 28: 535-41.

74. Heyworth BE, Lee JH, Kim PD, Lipton CB, Strauch RJ, Rosenwasser MP. Hylan versus corticosteroid versus placebo for treatment of basal joint arthritis: a prospective, randomized, double-blinded clinical trial. J Hand Surg Am. 2008; 33: 40-8.

75. Bahadir C, Onal B, Dayan VY, Gurer N. Comparison of therapeutic effects of sodium hyaluronate and corticosteroid injections on trapeziometacarpal joint osteoarthritis. Clin Rheumatol. 2009; 28: 529-33.

76. Roux C, Fontas E, Breuil V, Brocq O, Albert $\mathrm{C}$, Euller-Ziegler L. Injection of intra-articular sodium hyaluronidate (Sinovial) into the carpometacarpal joint of the thumb (CMC1) in osteoarthritis. A prospective evaluation of efficacy. Joint Bone Spine. 2007; 74: 368-72.

77. Coaccioli S, Pinoca F. Short term efficacy of intra-articular injection of hyaluronic acid in osteoarthritis of the first carpometacarpal joint in a preliminary open pilot study. Clin Terap. 2006; 157: 321-5.

78. Salini V, De Amicis D, Abate M, Natale MA, Di Iorio A. Ultrasound-guided hyaluronic acid injection in carpometacarpal osteoarthritis: short-term results. Int J Immunopathol Pharmacol. 2009; 22: 455-60.

79. Mandl LA, Hotchkiss RN, Adler RS, Lyman S, Daluiski A, Wolfe SW, et al. Injectable hyaluronan for the treatment of carpometacarpal osteoarthritis: open label pilot trial. Curr Med Res Opin. 2009; 25: 2103-8.

80. Frizziero L, Frizziero A, Giordan N. A retrospective study of intra-articular sodium hya- luronate (MW 500-730 KDA) injection for trapeziometacarpal joint osteoarthritis. Osteoarthritis Cartilage. 2012; 20: S175-6.

81. Joshi R. Intraarticular corticosteroid injection for first carpometacarpal osteoarthritis. J Rheumatol. 2005; 32: 1305-6.

82. Meenagh GK, Patton J, Kynes C, Wright GD. A randomized controlled trial of intra-articular corticosteroid injection of the carpometacarpal joint of the thumb in osteoarthritis. Ann Rheum Dis. 2004; 63: 1260-3.

83. Swindells G, Logan AJ, Armstrong DJ, Chan $\mathrm{P}$, Burke FD, Lindau TR. The benefit of radiologically-guided steroid injections for trapeziometacarpal osteoarthritis. Ann R Coll Surg Engl. 2010; 92: 680-4.

84. Maarse W, Watts AC, Bain GI. Medium-term outcome following intra-articular corticosteroid injection in first CMC joint arthritis using fluoroscopy. Hand Surg. 2009; 14: 99-104.

85. Wajon A, Carr E, Edmunds I, Ada L. Surgery for thumb (trapeziometacarpal joint) osteoarthritis. Cochrane Database Syst Rev. 2009; CD004631.

86. Vermeulen GM, Slijper H, Feitz R, Hovius SE, Moojen TM, Selles RW. Surgical management of primary thumb carpometacarpal osteoarthritis: a systematic review. J Hand Surg. 2011; 36: 157-69.

87. Ulrich-Vinther M, Puggaard H, Lange B. Prospective 1-year follow- up study comparing joint prosthesis with tendon interposition arthroplasty in treatment of trapeziometacarpal osteoarthritis. J Hand Surg. 2008; 33: 1369-77.

88. Atroshi I, Axelsson G, Nilsson EL. Osteotomy versus tendon arthroplasty in trapeziometacarpal arthrosis: 17 patients followed for 1 year. Acta Orthop Scand. 1998; 69: 287-90.

89. Punzi L, Canesi B, Carrabba M, Cimmino MA, Frizziero L, Lapadula G, et al. Italian consensus on Eular 2003 recommendations for the treatment of knee osteoarthritis. Reumatismo. 2004; 56: 190-201.

90. Punzi L, Doherty M, Zhang W, Cimmino MA, Carrabba M, Frizziero L, et al. Italian Consensus on EULAR recommendations 2005 for the management of hip osteoarthritis. Reumatismo. 2006; 58: 301-9.

91. Zhang W, Robertson J, Jones AC, Dieppe PA, Doherty M. The placebo effect and its determinants in osteoarthritis: meta-analysis of randomized controlled trials. Ann Rheum Dis. 2008; 67: 1716-23.

92. Maheu E, Altman RD, Bloch DA, Doherty M, Hochberg MC, Mannoni A, et al. Design and conduct of clinical trials in patients with osteoarthritis of the hand: recommendations from a task force of the Osteoarthritis Research Society International. Osteoarthritis Cartilage. 2006; 14: 303-22. 